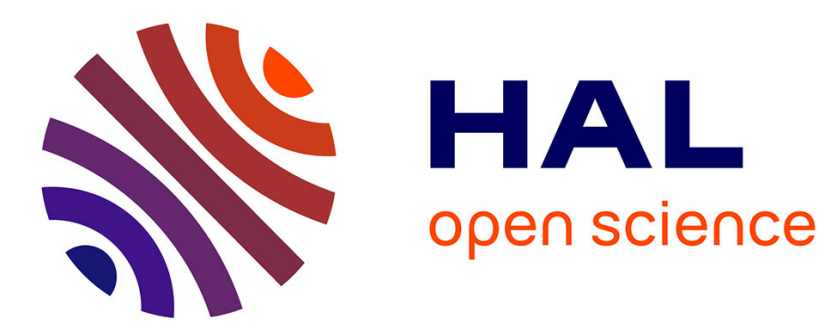

\title{
Modelling of the Non Isothermal Cyclic Behaviour of a Polycrystalline Cu Zn Al Shape Memory Alloy
}

\author{
G. Bourbon, C. Lexcellent, S. Leclercq
}

\section{To cite this version:}

G. Bourbon, C. Lexcellent, S. Leclercq. Modelling of the Non Isothermal Cyclic Behaviour of a Polycrystalline $\mathrm{Cu} \mathrm{Zn} \mathrm{Al} \mathrm{Shape} \mathrm{Memory} \mathrm{Alloy.} \mathrm{Journal} \mathrm{de} \mathrm{Physique} \mathrm{IV} \mathrm{Proceedings,} \mathrm{1995,} 05$ (C8), pp.C8-221-C8-226. 10.1051/jp4:1995830 . jpa-00254079

\section{HAL Id: jpa-00254079 https://hal.science/jpa-00254079}

Submitted on 1 Jan 1995

HAL is a multi-disciplinary open access archive for the deposit and dissemination of scientific research documents, whether they are published or not. The documents may come from teaching and research institutions in France or abroad, or from public or private research centers.
L'archive ouverte pluridisciplinaire HAL, est destinée au dépôt et à la diffusion de documents scientifiques de niveau recherche, publiés ou non, émanant des établissements d'enseignement et de recherche français ou étrangers, des laboratoires publics ou privés. 


\title{
Modelling of the Non Isothermal Cyclic Behaviour of a Polycrystalline $\mathrm{Cu} \mathrm{Zn}$ Al Shape Memory Alloy
}

\author{
G. Bourbon, C. Lexcellent and S. Leclercq \\ Laboratoire de Mécanique Appliquée, Faculté des Sciences, 25030 Besançon cedex, France
}

\begin{abstract}
In this paper, a model describing the behaviour of Shape Memory Alloys (SMA) under constant applied stress and thermal cycling is developed. This is the first (and necessary) step to obtain a coherent modelling of the well-known Two Way Shape Memory Effect (TWSME) exhibited by SMA after a training process. Two different mechanisms characteristic to SMA are involved in the present description. The first one is related to training itself, whose macroscopic manifestation is the appearance of a permanent strain. The second one concerns the response of SMA to non-isothermal loading. It can be solved by the introduction of news variables in the internal variables set. There are the volume fraction of self-accommodating martensite (pure thermal effect) and the volume fraction of "oriented" martensite (thermo-mechanical effect). The comparison between simulation and our experimental results on $\mathrm{Cu} \mathrm{Zn} \mathrm{Al} \mathrm{polycrystals} \mathrm{is} \mathrm{fairly} \mathrm{good.}$
\end{abstract}

\section{INTRODUCTION}

It is known that controlled cyclic loading (sometimes called "mechanical training" process) stabilises the mechanical properties of SMA (i.e. Miyazaki [1], Tobushi et al. [2], Bourbon [3]). In particular, the training performed under constant tensile applied stress between two given temperatures $T_{1}$ and $T_{2}$ $\left(T_{1}>A_{F}^{0}, T_{2}<M_{F}^{0}\right.$ ) stabilises the hysteresis loop (strain, $\varepsilon$ versus temperature, $T$ ) observed in simple tension. The aim of the present note is the theoretical description of the SMA response under this loading. The general thermodynamic framework of Raniecki and Lexcellent [4] ( $R_{L}$ model) is chosen here as a reference. The more general modelling of the non isothermal behaviour of SMA (Leclercq et al. [5]) is also of interest to perform the non isothermal cyclic simulations (Bourbon [3]).

\section{EXPERIMENTAL PROCEDURE AND RESULTS}

\subsection{Material}

A polycrystalline SMA Cu-25.57 $\mathrm{Zn}-4.09 \mathrm{Al}$ (Wt \%) manufactured by Trefimetaux society is used. To perform experiments, plates of thickness 2 millimeters are machined. The thermal treatment is the following:

(i) maintaining $20 \mathrm{~min}$ at $850^{\circ} \mathrm{C}$

(ii) oil quenching $\left(100^{\circ} \mathrm{C}\right)$

(iii) drawing temperature at $100^{\circ} \mathrm{C}$ during $60 \mathrm{~min}$.

By resistivity measurements, one founds the following values of characteristic temperatures at stress free state $(\sigma=0)$ :

$$
\mathrm{M}_{\mathrm{F}}^{0}=30^{\circ} \mathrm{C}, \mathrm{M}_{\mathrm{S}}^{0}=40^{\circ} \mathrm{C}, \mathrm{A}_{\mathrm{S}}^{0}=42^{\circ} \mathrm{C}, \mathrm{A}_{\mathrm{F}}^{0}=52^{\circ} \mathrm{C}
$$




\subsection{Experimental results}

In the austenitic state with $\mathrm{T}_{\text {eff }}=\mathrm{A}_{\mathrm{F}}^{0}+40^{\circ} \mathrm{C}$ a stress is applied. Its value is lower than the yield phase transition stress $\sigma^{\mathrm{AM}}\left(\mathrm{T}_{\text {eff }}\right)(\approx 145 \mathrm{MPa})$ obtained by tensile test at this temperature. This dead load being held, ten thermal cycles are performed (Figure 1). At last, the sample is unloaded.

A pure thermal cycle (at stress free state) permits to measure the training amplitude (TWSME).

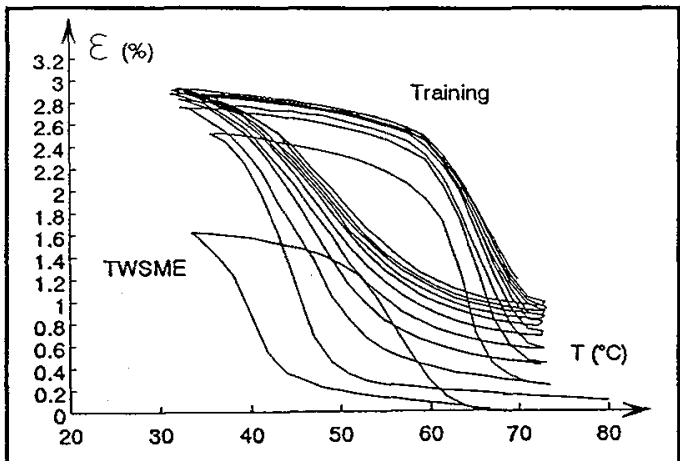

a) $\sigma=65 \mathrm{MPa}$

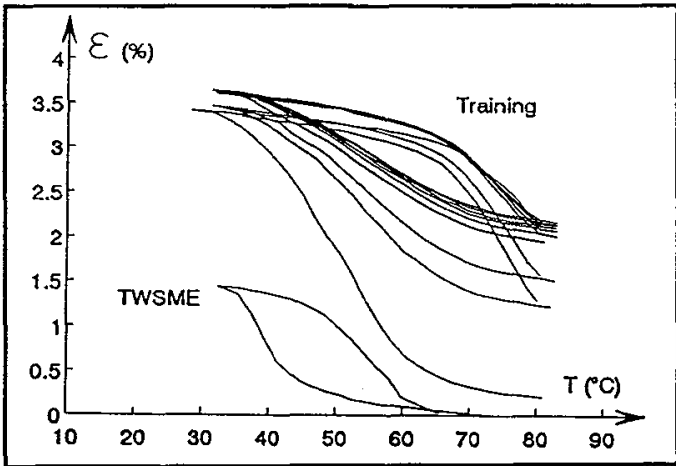

c) $\sigma=100 \mathrm{MPa}$

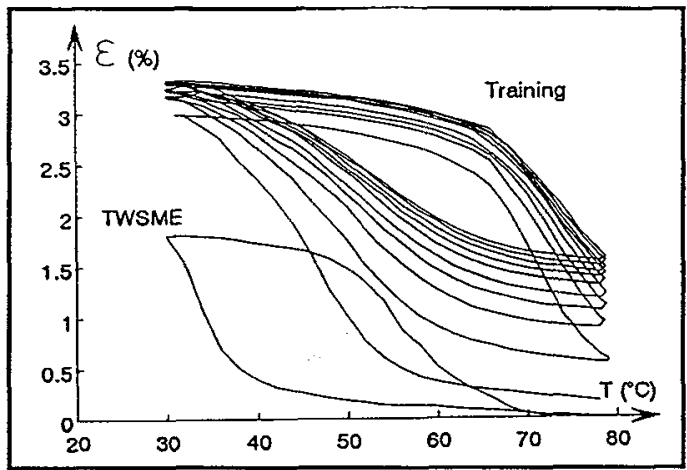

b) $\sigma=80 \mathrm{MPa}$

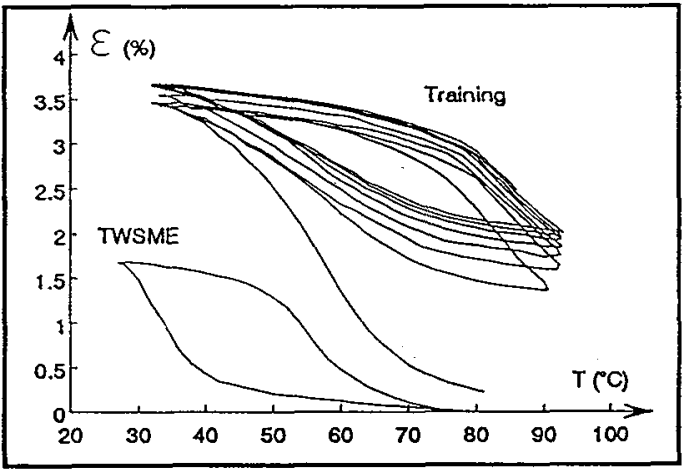

d) $\sigma=124 \mathrm{MPa}$

Figure 1 : Experimental results in non-isothermal loading

\subsection{Discussion}

First, one has to point out the important role played by the stress in the training process. The figure 2 illustrate this statement. It shows

(i) $\quad \varepsilon^{A M}(N=1)$ strain obtained at the first cooling

(ii) TWSME $(\sigma=0)$

(iii) $\mathrm{M}_{\mathrm{S}}^{\sigma}$ start transformation temperature

It is obvious here that $\varepsilon^{\mathrm{AM}}(\mathrm{N}=1)$ and TWSME have the same evolution with respect to the stress. Moreover both values increase while increasing the applied constant stress. From the same wiewpoint one can note that the increase of $M_{S}^{\sigma}$ seems to be linear while $\varepsilon^{A M}(N=1)$ and TWSME exhibit a saturation and a non linear behaviour.

These results are in agreement with the ones of Xu and Tan [6], showing that the value obtained at the first cooling $\left(\varepsilon^{\mathrm{AM}}(\mathrm{N}=1)\right)$ gives the training efficiency. 


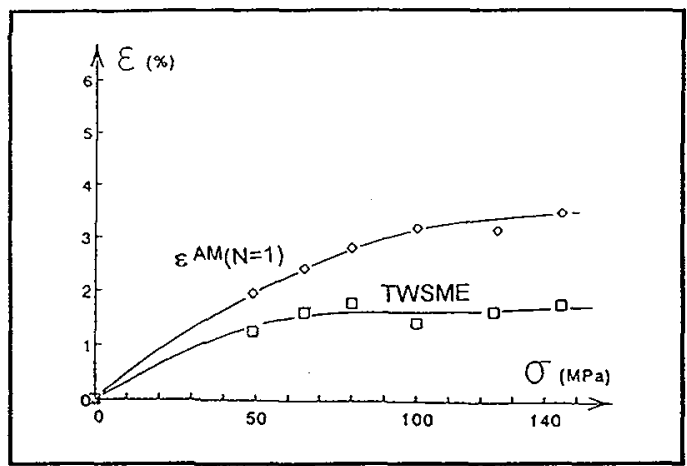

a) Evolution of $\varepsilon^{\mathrm{AM}}(\mathrm{N}=1)$ and TWSME (our polycrystal)

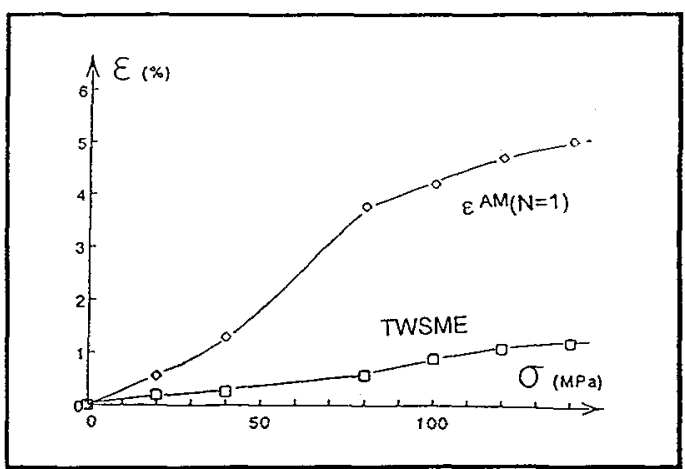

b) Evolution of $\varepsilon^{A M}(N=1)$ and TWSME $\mathrm{Xu}$ and Tan polycrystal [6]

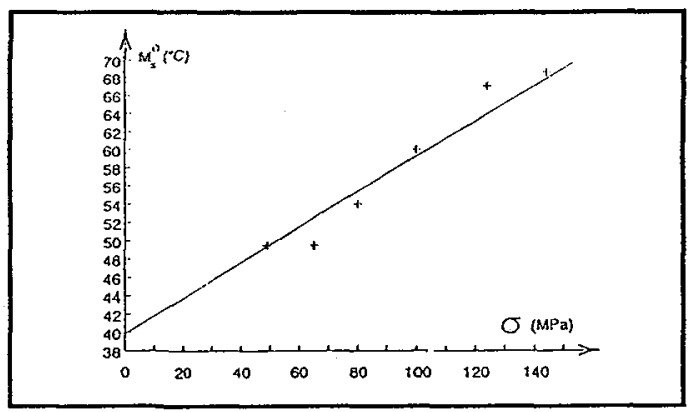

c) Evolution of $M_{s}^{\sigma}$

Figure 2 : influence of the constant applied stress in non isothermal training procedure

The training procedure of SMA is responsible for the variation of some material properties during a certain number of cycling processes (Fig. 2). This number of cycles varies with respect to metallurgical composition of the alloys and heat treatments. Nevertheless, material properties can be considered as constant (let say "stabilised") after the number of cycles necessary to train the SMA. The macroscopic measure of this stabilised cycle can be the irreversible strain created during cycling, or the volume fraction of permanent oriented martensite inside the material (let us call this variable $h$ in the following). The figure 3 proves the stabilisation trend of two important parameters, $h$ and $\mathbf{M}_{s}^{\sigma}$.

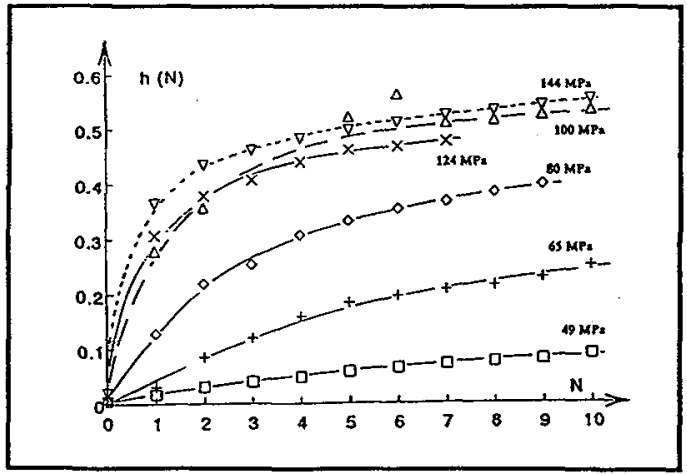

a) Evolution of $h$

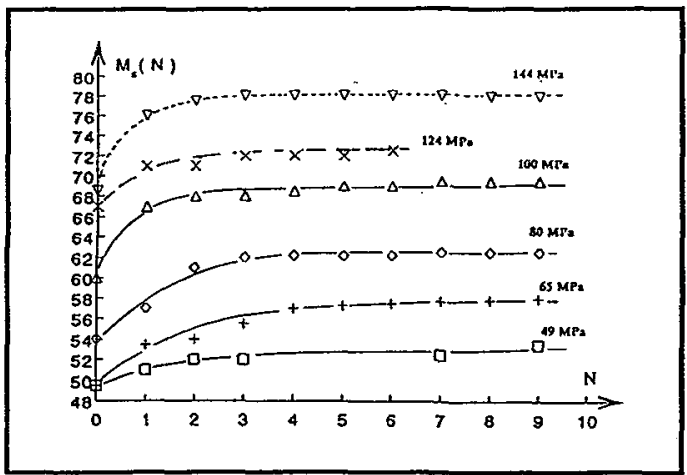

b) Evolution of $\mathbf{M}_{\mathbf{s}}^{\sigma}$

Figure 3 : Evolution of $h$ and $M_{\S}^{q}$ with respect to the number of cycles 


\section{NON ISOTHERMAL CYCLIC BEHAVIOUR MODELLING}

\subsection{Theoretic procedure}

Here two difficulties have to be taken into account. The first one is the non-isothermal behaviour of SMA. Indeed, even if the pseudoelastic (isothermal) behaviour can be nowadays considered as a standard one, the effect of temperature changes on the general response of SMA remains not well solved. Among the different interpretations that have already been given, the present authors choose to build a model based on thermodynamics of irreversible processes, following the way of so-called $R_{L}$ model [4]. To this aim the internal variable $\mathrm{z}$ governing the volume fraction of martensite inside the material is split into two ones [7]. Thus $\mathrm{z}_{\mathrm{T}}$ is related to self-accommodating martensite, induced by pure thermal effect, with no influence on the macroscopic behaviour. The second internal variable, called $z_{\sigma}$, represents the oriented martensite. Let us point out that this second martensite is to be created by at least a mechanical loading.

The second problem is related to the cyclic effect. From remarks explicated above, clearly only the oriented martensite is responsible for the appearance of phase transition strain. Moreover, a lot of experimental data explicitly show that the training process (i.e. the cyclic effect) creates some "irreversible" strain, which increases and saturates with respect to the number of loading cycles. With the help of these two observations, the authors choose to represent the cyclic effect by introducing an internal variable $h=z_{\sigma}^{r}$ ("r" for "retained") in addition to the set of state variables ( $\varepsilon$ : one dimensional macroscopic strain, $\mathrm{T}$ : temperature, $\mathrm{z}_{\mathrm{T}}, \mathrm{z}_{\sigma}$ ). This means that the residual strain is assumed to correspond to the existence of some retained martensite inside the material.

Thus, a specific free energy for the system is postulated :

$$
\psi=(1-z) \cdot \psi^{(1)}+z_{T} \cdot \psi^{(2)}+z_{\sigma} \cdot \psi^{(3)}+\Delta \psi
$$

Here, $\psi^{(\alpha)}$ ( $\alpha=1$ : austenite, $\alpha=2$ : self-accommodating martensite, $\alpha=3$ : oriented martensite) is the free energy of each phase. It is assumed to contain a term responsible for the training effect.

In the frame of a small strain assumption, the total macroscopic strain of the specimen is written in the following way:

$$
\varepsilon=\varepsilon^{\mathfrak{e}}+\varepsilon^{\mathrm{tr}}
$$

where $\varepsilon^{e}$ and $\varepsilon^{t r}$ are the elastic and transformation strain, respectively.

Following the general assumption made by Raniecki et al [8], and taking into account the one dimensional hypothesis, the transformation strain can be written as follows

$$
\varepsilon^{\mathrm{tr}}=\gamma \cdot z_{\sigma}
$$

and the constitutive equation governing the SMA behaviour writes ( $E$ is the Young's modulus)

$$
\sigma=\mathbf{E} \cdot \varepsilon^{e} .
$$

One has now to introduce the "phase transition criterion" concept, which has been largely discussed in [8]. It is closely related to the Clausius-Duhem inequality, and writes

austenite $\leftrightarrow$ self-accommodating martensite $\Pi_{\sigma}^{f}=\Pi_{0}^{f}+\frac{\gamma \cdot \sigma}{\rho}-(1-2 z) \cdot \phi_{i t}+\Delta \Pi_{0}^{f}(h, T)=0$

austenite $\leftrightarrow$ oriented martensite

$$
\Pi_{\mathrm{T}}^{\mathrm{f}}=\Pi_{0}^{\mathrm{f}}-(1-2 \mathrm{z}) \cdot \phi_{\mathrm{it}}=0
$$


with $\Pi_{0}^{f}=\Delta \mathrm{u}^{*}-\mathrm{T} \cdot \Delta \mathrm{s}^{*}$ and $\phi_{\mathrm{it}}=\overline{\mathrm{u}}_{0}-\mathrm{T} \cdot \overline{\mathrm{s}}_{0}$.

The cyclic term $\Delta \Pi_{0}^{\mathrm{r}}(\mathrm{h}, \mathrm{T})$ is equal to $(\Delta \overline{\overline{\mathrm{u}}}-\mathrm{T} \cdot \Delta \overline{\overline{\mathrm{s}}}) \cdot\left(-\frac{1}{2} \mathrm{~h}^{2}+\mathrm{h}_{\infty} \cdot \mathrm{h}\right)$

$\Delta \mathrm{u}^{*}, \Delta \mathrm{s}^{*}, \overline{\mathrm{u}}_{0}, \overline{\mathrm{s}}_{0}, \gamma, \rho, \Delta \overline{\overline{\mathrm{u}}}, \Delta \overline{\overline{\mathrm{s}}}, \mathrm{h}_{\infty}$ are material constants

$h_{\infty}$ has a specific meaning. It corresponds to the amount of permanent oriented martensite inside the material after training (the material properties are assumed to be constant). Thus, $h_{\infty}$ can be determined directly from the figure 3 .

Kinetic equations for internal variables are to be defined, in order to close the set of equations necessary to describe the non-isothermal cyclic behaviour of SMA. The first one concerns the phase transition process, and is contained in the following system :

For austenite $\rightarrow$ martensite phase transition

$$
\left\{\begin{array}{l}
d z_{\sigma}=-\left(1-z_{\sigma}\right) \cdot b_{1} \cdot d T \\
d z_{T}=-a_{1}^{T} \cdot\left(1-z_{T}\right) \cdot d T
\end{array}\right.
$$

For martensite $\rightarrow$ austenite phase transition

$$
\left\{\begin{array}{l}
\mathrm{dz}_{\sigma}=-\mathrm{z}_{\sigma} \cdot \mathrm{b}_{2} \cdot d \mathrm{~T} \\
\mathrm{dz_{ \textrm {T } }}=-\mathrm{a}_{2}^{\mathrm{T}} \cdot \mathrm{z}_{\mathrm{T}} \cdot \mathrm{dT}
\end{array}\right.
$$

where $a_{1}^{\mathrm{T}}, \mathrm{b}_{1}, \mathrm{a}_{2}^{\mathrm{T}}, \mathrm{b}_{2}$ are material constants.

The second kind of relation has to govern the evolution of internal variable $h$, which is the macroscopic measure for the cyclic effect. From experiments a reasonable formulation for $h$ is :

$$
\begin{aligned}
\dot{\mathrm{h}}=\mathrm{m}_{0} \cdot\left(\mathrm{h}_{\infty}-\mathrm{h}\right)^{\mathrm{P}} \cdot\left\langle\dot{\mathrm{z}}_{\sigma}\right\rangle & \\
\text { where } \quad\langle\bullet & =\bullet \text { if } \bullet>0 \\
& =0 \text { otherwhise }
\end{aligned}
$$

$\mathrm{m}_{0}, \mathrm{~h}_{\infty}, \mathrm{p}$ are material parameters directly related to the decrease of the yield stress and the increase of the permanent strain with respect to the number of cycles.

\subsection{Simulation}

The modelling of experimental results ( see Fig. 1) is pretty good (Fig 4 a, b). Moreover, the increase of the strain and the transformation temperatures with the number of cycles $\mathrm{N}$ is taken into account by this prevision.

\begin{tabular}{|c|c|c|c|c|c|c|}
\hline $\mathrm{E}(\mathrm{MPa})$ & $\rho\left(\mathrm{Kg} / \mathrm{m}^{3}\right)$ & $\gamma$ & $\Delta \mathrm{u}^{*}(\mathrm{~J} / \mathrm{Kg})$ & $\overline{\mathbf{u}}_{0}(\mathrm{~J} / \mathrm{Kg})$ & $\Delta \mathrm{s}^{*}(\mathrm{~J} / \mathrm{Kg} \mathrm{K})$ & $\overline{\mathrm{s}}_{0}(\mathrm{~J} / \mathrm{Kg} \mathrm{K})$ \\
\hline $5,84 \cdot 10^{4}$ & 8000 & 0,038 & 4710 & 180 & 15.2 & 0,27 \\
\hline
\end{tabular}
\begin{tabular}{|c|c|c|c|c|}
\hline $\mathrm{a}_{1}^{\mathrm{T}}$ & $\mathrm{a}_{2}^{\mathrm{T}}$ & $\mathrm{b}_{1}$ & $\mathrm{~b}_{2}$ \\
\hline 0,46 & 0,46 & 0,07 & 0,15 \\
\hline
\end{tabular}

Table 1 : non-isothermal constants 


\begin{tabular}{|c|c|c|c|c|}
\cline { 2 - 5 } \multicolumn{1}{c|}{} & $\sigma_{0}=65 \mathrm{MPa}$ & $\sigma_{0}=80 \mathrm{MPa}$ & $\sigma_{0}=100 \mathrm{MPa}$ & $\sigma_{0}=124 \mathrm{MPa}$ \\
\hline $\mathrm{m}_{0}$ & 0,35 & 0,495 & 1,2 & 2,12 \\
\hline $\mathrm{p}$ & 0,96 & 0,96 & 1,4 & 1,89 \\
\hline $\mathrm{h}_{\infty}$ & 0,263 & 0,421 & 0,553 & 0,566 \\
\hline
\end{tabular}

a)

\begin{tabular}{|c|c|}
\hline$\Delta \overline{\overline{\mathrm{u}}}(\mathrm{J} / \mathrm{Kg})$ & $\Delta \overline{\overline{\overline{\mathrm{s}}}}(\mathrm{J} / \mathrm{Kg})$ \\
\hline 46500 & 136 \\
\hline
\end{tabular}

b)

Table 2 : cyclic constants

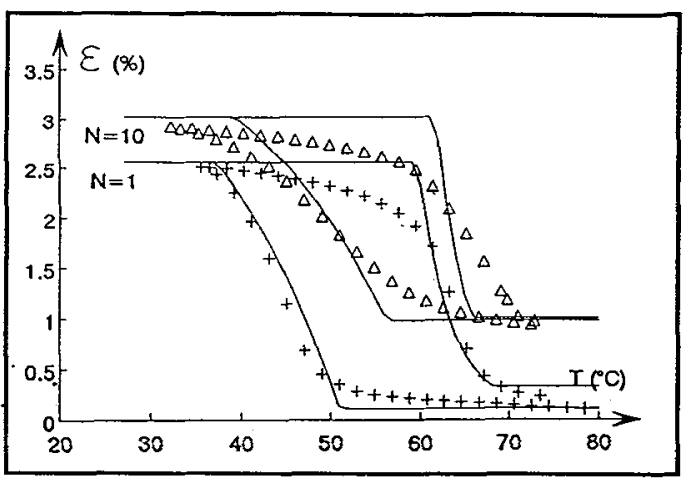

a) $\sigma=65 \mathrm{MPa}$

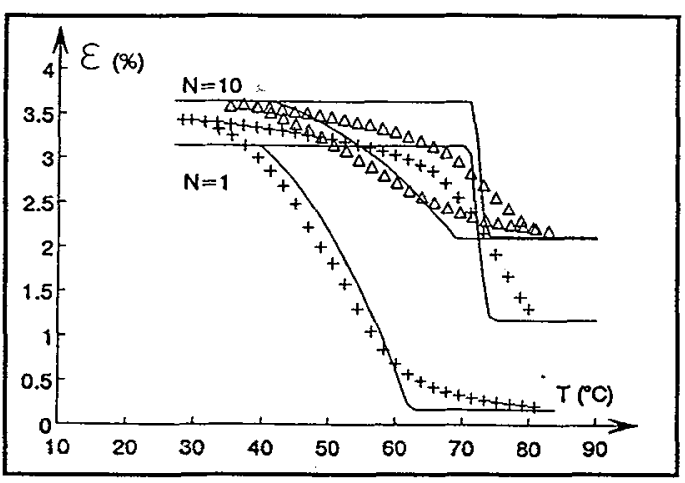

b) $\sigma=100 \mathrm{MPa}$

Figure 4 : Modelling of non-isothermal cyclic behaviour (see Fig. 1) (+ or $\Delta$ experimental — modelling)

\section{CONCLUSION}

Under constant applied stress, thermal cycling performed on $\mathrm{Cu} \mathrm{Zn}$ Al SMA polycrystal constitutes a good training process. The modelling of SMA behaviour under constant stress and thermal cycling has been successfully performed. This required the addition of new internal variables to the so called $R_{\mathrm{L}}$-model, which was considered as a reference. Nevertheless, even if the present model predicts the appearance of TWSME after training (governed by the term $\Delta \Pi_{0}^{f}(\mathrm{~h}, \mathrm{~T})$ in eq. $5 \mathrm{a}$ ), some simple calculations have shown this prediction was only a qualitative one. It is thus necessary to improve the present modelling to take into account quantitatively the TWSME. This could be performed with some kinematic variable, or directly in the writing of the free energy.

\section{References}

[1] Miyazaki S., "Thermal and stress cycling effects and fatigue properties of Ti Ni alloys." Duerig TW et al (Eds) Engineering aspects of shape memory alloys Butterworth-Heineman Ltd (1990) 394-413

[2] Tobushi H., Iwanaga H., Tanaka K., Hori T. and Sawada T., Cont. Mech. Therm. 3 (1991) 79-93

[3] Bourbon G. "Contribution à l'étude du comportement cyclique isotherme et anisotherme des alliages à mémoire de forme." Thèse $n^{\circ} 410$, Université de Franche-Comté (1994)

[4] Raniecki B. and Lexcellent C. Eur J. Mech. A/Solids, 13,1 (1994) 21-50

[5] Leclercq S., Bourbon G. and Lexcellent C. "Plasticity like model of martensite phase transition in shape memory alloys." III European Symposium on martensitic transformations Barcelona, 14-16 Sept., (1994)

[6] Xu H. and Tan S. Scripta Met. Mat. 25 (1991) 1507-1511

[7] Brinson L.C. J. of Int Syst. and Struct. (1991) 275-309

[8] Raniecki B., Lexcellent C. and Tanaka K., Arch. Mech., 44, 3 (1992), 261-284 